\title{
Upper mantle anisotropy from teleseismic SKS splitting beneath Lützow-Holm Bay region, East Antarctica
}

\author{
Y. Usui, ${ }^{1}$ M. Kanao, ${ }^{2}$ A. Kubo, ${ }^{3}$ Y. Hiramatsu ${ }^{4}$, and H. Negishi ${ }^{5}$ \\ ${ }^{1}$ Transdisciplinary Research Integration Center, Research Organization of Information and Systems, 1-9-10 Kaga, Itabashi-ku, Tokyo, 173-8515, Japan \\ (y.usui@nipr.ac.jp) \\ ${ }^{2}$ National Institute of Polar Research (NIPR), 1-9-10 Kaga, Itabashi-ku, Tokyo, 173-8515, Japan (kanao@nipr.ac.jp) \\ ${ }^{3}$ Kochi Earthquake Observatory, Kochi University, 2-17-47, Asakura Honmachi, Kochi, 780-8073, Japan (akubo@cc.kochi-u.ac.jp) \\ ${ }^{4}$ Graduate School of Natural Science and Technology, Kanazawa University, Kakuma-machi, Kanazawa, 920-1192, Japan \\ (yoshizo@hakusan.s.kanazawa-u.ac.jp) \\ ${ }_{5}^{5}$ Earthquake Disaster Mitigation Research Center (NIED), 1-5-2 Wakinohama-Kaigandori, Chuo, Kobe, 651-0073, Japan (negishi@bosai.go.jp)
}

\begin{abstract}
Investigations of SKS wave splitting of teleseismic events from digital seismographs recorded at eight stations around the Lützow-Holm Bay Region have lead to understanding the evolution of the Antarctic Plate. The observed delay times of SKS splitting are up to $1.3 \mathrm{~s}$, which are generally equal to the global average. A two-layer model reveals that the lower layer anisotropy is caused by the recent asthenospheric flow, as compared with the Absolute Plate Motion by the HS3-NUVEL1 model. The upper layer anisotropy corresponds well to polarization of NE-SW convergence direction between East and West Gondwana in Pan-African age. We suggest that the upper layer anisotropy was formed during Pan-African orogeny and was possibly influenced by the preexisting structure during Gondwana break-up. The origin of anisotropy is the Lattice Preferred Orientation of olivine which was caused by both paleo-tectonic events and the recent asthenospheric flow.
\end{abstract}

Citation: Usui, Y., M. Kanao, A. Kubo, Y. Hiramatsu, and H. Negishi (2007), Upper mantle anisotropy from teleseismic SKS splitting beneath Lützow-Holm Bay region, East Antarctica: A Keystone in a Changing World-Online Proceedings of the $10^{\text {th }}$ ISAES, edited by A. K. Cooper and C. R. Raymond et al., USGS Open-File Report 2007-1047, Short Research Paper 013, 4 p.; doi:10.3133/of2007-1047.srp013.

\section{Introduction}

In recent years, we have understood the stress and strain fields of the Earth's interior through many approaches associated with geodynamics, such as mantle convection. The analysis of seismic anisotropy has developed into an important tool to understand deformation in the Earth's interior. Seismic anisotropy is mainly produced by the Lattice Preferred Orientation (LPO) of highly anisotropic mantle peridotites (Nicolas and Christensen, 1987). Petrophysical studies suggest that the anisotropy is mainly restricted to the olivine stability field, i.e. above $410 \mathrm{~km}$ depth, in the lithosphere and/or asthenosphere (Mainprice and Silver, 1993). Some contributions from the lowermost mantle (Kendall and Silver, 1998) and the crust (Herquel et al., 1995) cannot be ruled out.

In previous studies of shear wave splitting, the range of delay times is generally up to $3.6 \mathrm{~s}$ (e.g. Heintz et al. 2003), and the global average beneath Precambrian cratons is 1.0 1.8 s (e.g. Silver, 1996; Heintz and Kennet, 2005). Intrinsic shear wave anisotropy is within the range of $2 \sim 4.5 \%$ and requires a $100 \sim 300 \mathrm{~km}$ thick anisotropic layer to account for the observed splitting time (Mainprice and Silver, 1993; Ben Ismail and Mainprice, 1998). The origin of such anisotropy is generally attributed to the deformations due to the present plate motion that reflects the mantle flow and paleo-tectonic events of collision and/or break-up of cratons (Vinnik et al., 1992; Kubo et al., 1995).

The studies of upper mantle anisotropy have been already reported at most permanent seismic stations in the Antarctic (Kubo et al., 1995; Pondrelli and Azzara, 1998; Barruol and Hoffmann, 1999; Müller, 2001). In the

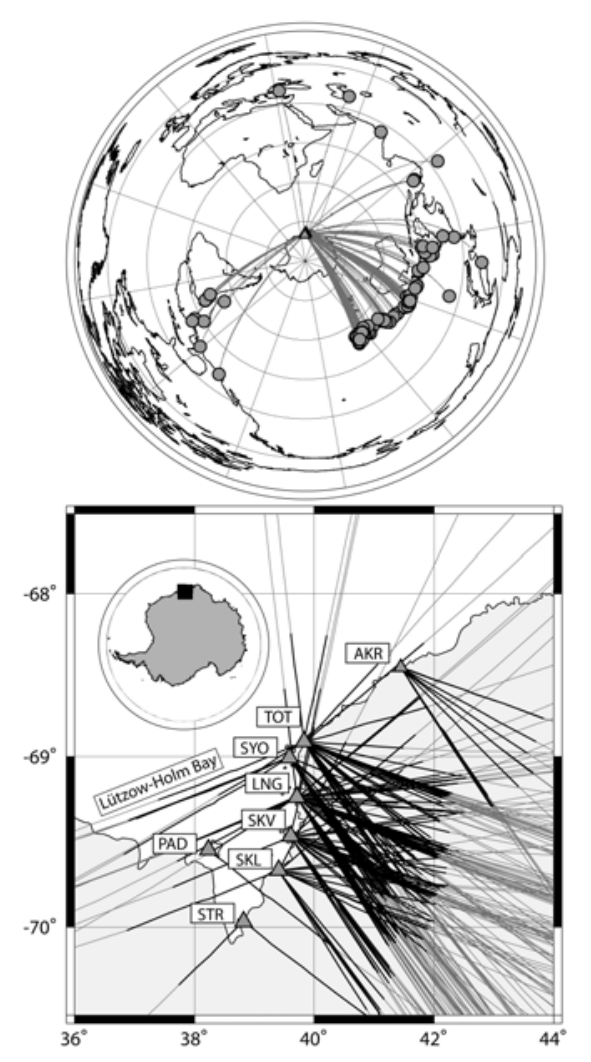

Figure 1. (top) The global distribution of sources (gray circles) and stations (triangles). Gray lines are ray paths. (bottom) Map of the study area showing the seismic stations (triangles). Gray lines indicate SKS wave paths and black lines those wave paths above $410 \mathrm{~km}$ depth. 
Table 1. List of station coordinate and averaged splitting parameters of each station. In the case of a two-layer modeling, the parameters of both layers are shown.

\begin{tabular}{|c|c|c|c|c|c|c|c|}
\hline Station & $\begin{array}{c}\text { Latitude } \\
\text { (deg.) }\end{array}$ & $\begin{array}{c}\text { Longitude } \\
\text { (deg.) }\end{array}$ & $\begin{array}{l}\text { Period } \\
\text { (year) }\end{array}$ & $\begin{array}{c}\phi \\
\text { (deg.) }\end{array}$ & $\begin{array}{c}\delta \mathrm{t} \\
\text { (sec.) }\end{array}$ & $\begin{array}{l}\text { Number of } \\
\text { waveforms }\end{array}$ & Comments \\
\hline AKR & -68.458 & 41.442 & 1999 2002 & $\begin{array}{c}144 \\
56\end{array}$ & $\begin{array}{l}0.6 \\
1.0\end{array}$ & 12 & $\begin{array}{l}\text { lower layer } \\
\text { upper layer }\end{array}$ \\
\hline LNG & -69.243 & 39.713 & 1999 2004 & $\begin{array}{c}118 \\
46\end{array}$ & $\begin{array}{l}0.2 \\
0.8\end{array}$ & 67 & $\begin{array}{l}\text { lower layer } \\
\text { upper layer }\end{array}$ \\
\hline PAD & -69.552 & 38.234 & 1996 & 66 & 0.7 & 1 & single \\
\hline SKL & -69.673 & 39.408 & 1999 2004 & $\begin{array}{c}146 \\
32\end{array}$ & $\begin{array}{l}0.3 \\
0.9\end{array}$ & 16 & $\begin{array}{l}\text { lower layer } \\
\text { upper layer }\end{array}$ \\
\hline SKV & -69.473 & 39.607 & 1999 2004 & $\begin{array}{l}48 \\
40\end{array}$ & $\begin{array}{l}0.3 \\
0.7\end{array}$ & 40 & $\begin{array}{l}\text { lower layer } \\
\text { upper layer }\end{array}$ \\
\hline STR & -69.970 & 38.820 & $1996 \sim 1997$ & - & - & 2 & No evidence \\
\hline SYO & -69.007 & 39.585 & 1990 2004 & $\begin{array}{c}145 \\
57\end{array}$ & $\begin{array}{l}0.4 \\
1.3\end{array}$ & 34 & $\begin{array}{l}\text { lower layer } \\
\text { upper layer }\end{array}$ \\
\hline TOT & -68.912 & 39.828 & 1999 2004 & $\begin{array}{c}120 \\
48\end{array}$ & $\begin{array}{l}0.2 \\
1.0\end{array}$ & 42 & $\begin{array}{l}\text { lower layer } \\
\text { upper layer }\end{array}$ \\
\hline
\end{tabular}

Lützow-Holm Bay Region (LHB, Fig. 1), East Antarctica, the anisotropy was obtained at Syowa Station (SYO: Kubo et al., 1995) and spatial distributions of the anisotropy in LHB were unknown. Therefore, we analyze seismic waveform data of field deployed stations near the coast to expand the study region from northeast to southwest. Our study used sufficient data to enable us to discuss the distribution of upper mantle anisotropy and the evolution of the Antarctic Plate, together with the effects of assembly and break-up process of Gondwana.

\section{Data and Analysis}

We used broad-band seismographs recorded at eight stations from 1996 to 2004 in LHB (Fig. 1). Table 1 displays the list of station coordinates and the analysis period of each station. The stations LNG, SKL, SKV, SYO and TOT have been recorded fully between 1996 and 2004 and recording has continued to the present (2007). In this study, we used the teleseismic data with moment magnitudes (Mw) greater than 5.6, and selected the events located within the epicentral distances of $85^{\circ} \sim 130^{\circ}$ from each station. For this distance range, SKS phases are clearly separated from direct S, $\mathrm{S}_{\text {diff, }}$ and ScS. We chose the data of good signal-to-noise ratio, having simple and impulsive source time function, for which we could easily identify the SKS arrivals. Thus the total number of events and analyzed waveforms is 156 and 214, respectively. For the station SYO, we analyzed the total number of 24 waveforms to obtain more accurate anisotropy beneath the vicinity of the station, in addition to 10 traces of the previous work of Kubo et al. (1995). The map of analyzed events and station location is shown in Figure 1.

Applying a band-pass filter $(0.02 \mathrm{~Hz}-0.2 \mathrm{~Hz})$ to all the waveform data, we estimate the splitting parameter $(\phi, \delta \mathrm{t})$ of teleseismic SKS waves assuming a single layer of hexagonal symmetry with a horizontal symmetry axis (Silver and Chan, 1991). $\phi$ is the fast direction of split shear wave and $\delta t$ is the delay time between the fast polarized wave and slow polarized wave. The method of finding $\phi$ and $\delta \mathrm{t}$ is based on net grid search technique from $0^{\circ}$ to $360^{\circ}$ and $0.0 \mathrm{~s}$ to $3.0 \mathrm{~s}$ (with intervals of $1^{\circ}$ and $0.1 \mathrm{~s}$ ), respectively. This is determined by minimizing the energy of the transverse component of reconstructed SKS seismograms just before incident to the anisotropic region. The error estimation of each combination of splitting parameters can be given by 95\% confidence level of $F$ test (Silver and Chan, 1988).

Figure 2 shows an example of the analysis. We clearly find SKS arrivals above noise level in the original waveforms of transverse component and the horizontal particle motion is elliptical (Fig. 2a). After removing the anisotropic effect, there is no SKS phase on the reconstructed transverse component and the particle motion displays linear motion. Figure $2 \mathrm{~b}$ shows a contour map of the calculated transverse energy as a function of variable splitting parameters. The minimum point can be determined well and the corresponding splitting parameters are clearly obtained.

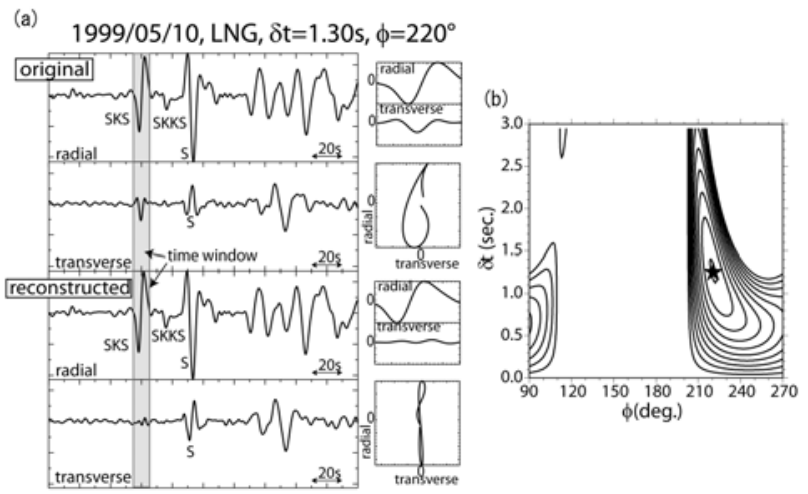

Figure 2. (a) An example of SKS waveforms and horizontal particle motions for both original seismograms (top) and reconstructed SKS waveforms by correction of the splitting parameters (bottom). (b) Contour map of the calculated transverse energy as a function of variable splitting parameters. Star is the optimum splitting parameter. 


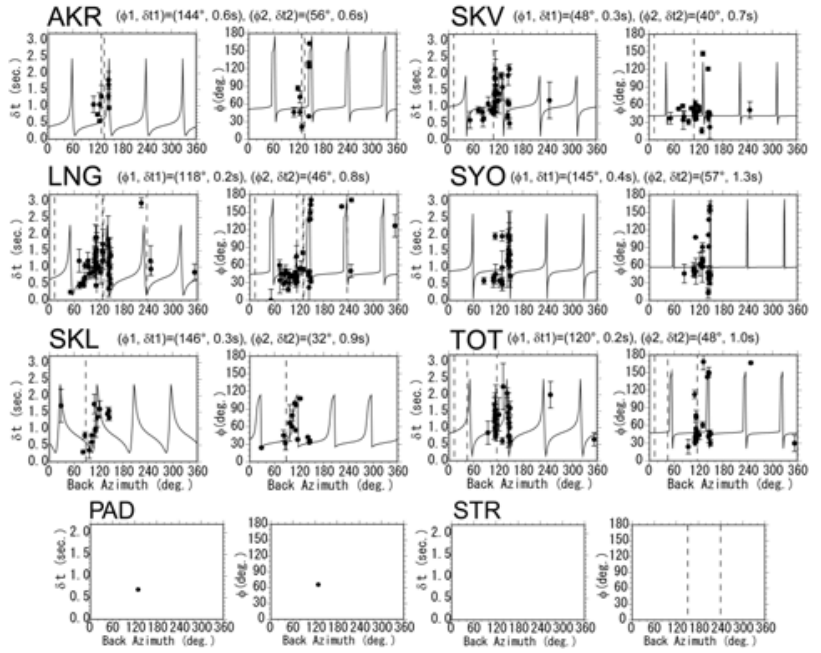

Figure 3. Splitting parameters of $\phi$ and $\delta$ t plotted as a function of back azimuth. Vertical dashed lines are the direction of null measurements. At stations AKR, LNG, SKL, SKV, SYO and TOT the azimuthal variations of apparent splitting parameters are modeled by a two-layer case of anisotropy. The parameter pair $\left(\phi_{1}, \delta \mathrm{t}_{1}\right)$ describes the lower layer anisotropy and $\left(\phi_{2}, \delta \mathrm{t}_{2}\right)$ describes the upper layer anisotropy.

For six stations (AKR, LNG, SKL, SKV, SYO and TOT), we can recognize the azimuthal variation of the splitting parameter (Fig. 3). In this case, we modeled a two-layer azimuthal anisotropy (Silver and Savage, 1994). We performed direct modeling of two horizontally layered structures and compared the predicted azimuthal variations of the anisotropy parameters to our observations. The parameters retrieved from a single layer assumption are apparent parameters, which may be fitted to a two-layer model with four independent parameters $\left(\phi_{1}, \delta t_{1}, \phi_{2}, \delta t_{2}\right)$, with index 1 corresponding to the lower layer and index 2 to the upper layer. We calculate the residual between observations and predicted curves and the optimum parameters pair is the minimum value of the root mean square of the residuals.

\section{Discussion}

Table 1 shows the splitting parameters of each station corresponding to the two-layer anisotropy. We also find evidence of no splitting, which is reported as 'null' in the conventional description for anisotropy, and it is consistent with the fast directions within $25^{\circ}$ (Fig. 3). For PAD and STR, unfortunately, we could analyze only two events and STR shows no clear evidence of SKS splitting in our data. However we observed two 'null' directions which may be associated with the fast polarization direction at STR.

Investigation of seismic anisotropy may contribute to ideas on the influence of recent and/or fossil mantle flows which reflect tectonic evolution of the study region. The fast polarization directions are generally compared with the directions of Absolute Plate Motion (APM), which reflects recent mantle flow (Vinnik et al., 1992). The directions of
APM around LHB are about $\mathrm{N} 145^{\circ} \mathrm{E}$ and the velocity is about $1.1 \mathrm{~cm} / \mathrm{yr}$ based on the HS3-NUVEL1 (Fig. 4; Gripp and Gordon, 2002). The fast polarization directions of the lower layer are generally parallel to the directions of APM. It is possible that the lower layer anisotropy reflects asthenospheric anisotropy due to LPO by the horizontal mantle flow along the APM.

In contrast, the fast polarization directions of the upper layers never coincide with the APM direction (the difference is up to $100^{\circ}$ ). We consider the anisotropic structure associated with past tectonic events of East Antarctica and the origin of anisotropy is "frozen" in the lithosphere. Gondwana assembly in Early Paleozoic is one of the major tectonic events in LHB. LHB experienced regional metamorphism among the Pan-African orogeny (e.g., Shiraishi et al., 1994; Fitzsimons, 2000). The metamorphic grade increases continuously from NE to SW along the coast and the maximum thermal axis lies in the southernmost part of the LHB as the NNW-SSE direction (Hiroi et al., 1991; Motoyoshi et al., 1989). By combining geophysical and lithologic data, LHB was considered to be formed under NE-SW convergence, perpendicular to the thermal axis, during collision between supra terrains of East and West Gondwana during the last stage of supercontinent formation (Ishikawa and Kanao, 2002; Kanao and Ishikawa, 2004). If LHB underwent NE-SW compression, the related paleo-mantle flow along this direction could produce the anisotropy associated with the

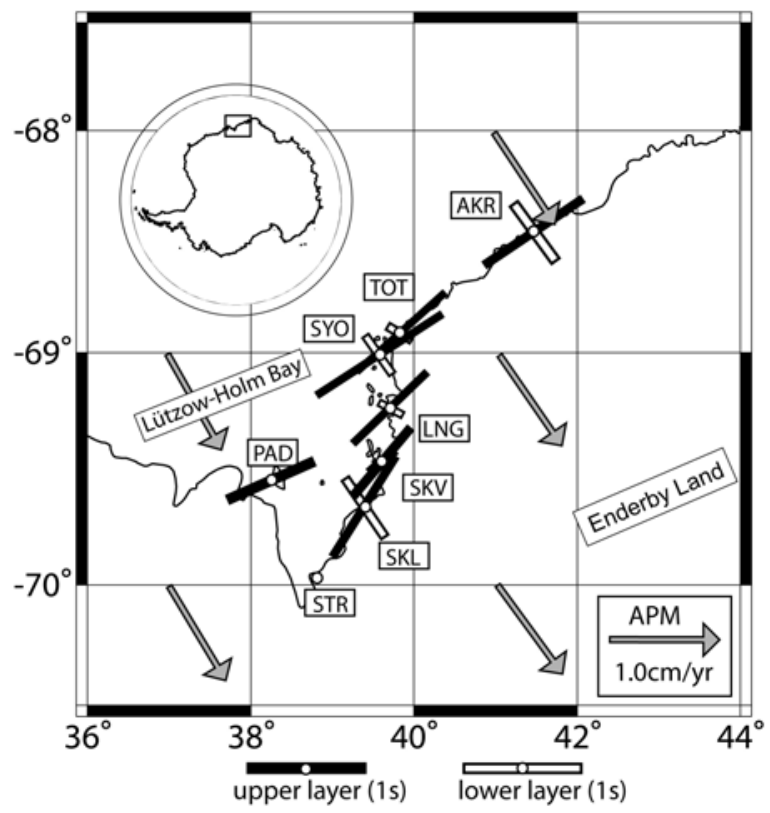

Figure 4. The obtained upper mantle anisotropy in LHB. At stations AKR, LNG, SKL, SYO and TOT, the lower layer anisotropy may have been produced by the recent asthenospheric mantle flow. At nearly all stations the directions of the upper layer anisotropy are parallel to NE-SW convergence during the Pan-African age. 
thermal axis of progressive metamorphism. Since the direction of the paleo-compression is consistent with our resultant fast polarization directions by SKS splitting, we conclude that the upper layer anisotropy is caused by the lithospheric deformation during the formation of LHB in the Pan-African age.

Tommasi and Vauchez (2001) suggested that the LPO-induced mechanical anisotropy developed along the direction of preexisting lithospheric structure during continental rifting. Müller (2001) proposed that the origin of the anisotropy beneath Western Dronning Maud Land, East Antarctica, was ancient lithospheric structure modified by rifting processes during Gondwana break-up. In LHB, the spreading direction off Enderby Land in the first stage of the Gondwana break-up was NW-SE (Nogi et al., 1996) and the strike of the rift is generally parallel to the continental margin. The fast polarization directions of the upper layer are roughly parallel to the continental margin in LHB. Therefore, it is plausible that break-up processes affected the formation of anisotropy in the upper layer. The preexisting lithospheric structure may also influence the formation of the anisotropy during Gondwana break-up.

\section{Conclusions}

We observed upper mantle shear wave splitting using teleseismic SKS waves in LHB, East Antarctica. We propose that the anisotropy is caused by the LPO of mantle minerals in response to the tectonic history of the region.. The seismic anisotropy is interpreted in terms of a two-layer model, in which the lower layer anisotropy is caused by recent asthenospheric mantle flow along APM directions, while the upper layer anisotropy is caused by plate convergence during Pan-African time involving Gondwana assembly, subsequently modified by rifting and continental break-up.

Acknowledgements The authors wish to thank Japanese Antarctic Research Expedition (JARE) $38 \sim 46$ and for National Institute of Polar Research (NIPR) for installing, maintaining, and operating the seismic station we used in this study. We also thank Paul Wessel and Walter Smith for use of Generic Mapping Tools (GMT; Wessel and Smith, 1991) and Peter Goldstein for use of Seismic Analysis Code (SAC). This research was partially supported by Function and Induction Research Project, Transdisciplinary Research Integration Center, Research Organization of Information and Systems. The authors are grateful to Maggy Heintz and Fabrice Fontaine for their reviews of the paper.

\section{References}

Barruol, G., and R. Hoffmann (1999), Upper mantle anisotropy beneath the Geoscope stations, J. Geophys. Res., 104, 10757-10774.

Ben-Ismail, W., and D. Mainprice (1998), An olivine fabric database: an overview of upper mantle fabrics and seismic anisotropy, Tectonophysics, 296, 145-157.

Fitzsimons, I. C. W. (2000), Grenville-age basement provinces in East Antarctica: Evidence for three separate collisional orogens, Geology, 28, 879-882.

Gripp, A.E., and R. G. Gordon (2002), Young tracks of hotspots and current plate velocities, Geophys. J. Int., 150, 321-361.

Heintz, M., and B. L. N. Kennet (2005), Continental scale shear wave splitting analysis: Investigation of seismic anisotropy underneath the Australian continent, Earth Planet. Sci. Lett., 236, 106-119.

Heintz, M., A. Vauchez, M. Assumpção, G. Barroul, and M. Egydio-Silva (2003), Shear wave splitting in SE Brazil: an effect of active or fossil upper mantle flow, or both?, Earth Planet. Sci. Lett., 211, 79-95.
Herquel, G., G. Wittlinger, and J. Guilbert (1995), Anisotropy and crustal thickness of Northern-Tibet. New constraints for tectonic modeling, Geophys. Res. Lett., 22, 1925-1928.

Hiroi, Y., K. Shiraishi, and Y. Motoyoshi (1991), Late Proterozoic paired metamorphic complexes in East Antarctica, with special reference to the tectonic significance of ultramafic rocks, Geological Evolution of Antarctica, edited by M. R. A. Thomson et al., pp 83-87, Cambridge Univ. Press.

Ishikawa, M., and M. Kanao (2002), Structure and collision tectonics of Pan-African orogenic belt - scientific significance of the geotransect for a supercontinent: Gondwanaland, Bull. Earthq. Res. Inst. Univ. Tokyo, 77, 287-302.

Kanao, M., and M. Ishikawa (2004), Origins of the lower crustal reflectivity in the Lützow-Holm Complex, Enderby Land, East Antarctica, Earth Planets Space, 56, 151-162.

Kendall, J. M., and P. G. Silver (1998), Investigating causes of D” anisotropy, Geodyn. Ser. 28, 97-118.

Kubo, A., Y. Hiramatsu, M. Kanao, M. Ando, and T. Terashima (1995), An analysis of the SKS splitting at Syowa station in Antarctica, Proc. NIPR Symp. Antarct. Geosci., 8, 25-34.

Mainprice, D., and P. G. Silver (1993), Interpretation of SKS-waves using samples from subcontinental lithosphere, Phys. Earth Planet. Inter., 78, 257-280.

Motoyoshi, Y., S. Matsubara, and H. Matsueda (1989), P-T evolution of the granulite facies rocks of the Lützow-Holm Bay region, East Antarctica, Evolution of Metamorphic Belts, edited by J. S. Daly et al., pp 325-329, Geol. Soc. Spec. Publ., 43.

Müller, C. (2001), Upper mantle seismic anisotropy beneath Antarctica and the Scotia Sea region, Geophys. J. Int., 147, 105-122.

Nicolas, A., and N. I. Christensen (1987), Formation of anisotropy in upper-mantle peridotites - a review, in Composition, Structure and Dynamics of the Lithosphere-Asthenosphere System, edited by K. Fuchs and C. Froidevaux, pp 111-123, AGU Geodyn. Ser., 71.

Nogi, Y., Seama, N. Isezaki, and Y. Fukuda (1996), Magnetic anomaly lineations and fracture zones deduced from vector magnetic anomalies in the West Enderby Basin, in Weddell Sea Tectonics and Gondwana Break-up, edited by B. C. Storey, E. C. King, E. C, and R. A. Livermore, pp 265-273, Geological Society Special Publication, 108.

Pondrelli, S., and R. Azzara (1998), Upper mantle anisotropy in Victoria Land (Antarctica), Pure Appl. Geophys, 151, 433-442.

Shiraishi, K., D. J. Ellis, Y. Hiroi, C. M. Fanning, Y. Motoyoshi, and Y. Nakai (1994), Cambrian Orogenic Belt in East Antarctica and Sri Lanka: Implications for Gondwana Assembly, J. Geol., 102, 47-65.

Silver, P. G. (1996), Seismic anisotropy beneath the continents: probing the depth of geology, Ann. Rev. Earth Planet. Sci., 24, 385-432.

Silver P. G., and W. W. Chan (1988), Implications for continental structure and evolution from anisotropy, Nature, 335, 34-39.

Silver P. G., and W. W. Chan (1991), Shear wave splitting and subcontinental mantle deformation, J. Geophys. Res., 96, 16,429-16,454.

Silver, P. G., and M. K. Savage (1994), The interpretation of shear-wave splitting in the presence of two anisotropic layers, Geophys, J. Int., 119, 949-963.

Tommasi, A., and A. Vauchez (2001), Continental rifting parallel to ancient collisional belts: an effect of the mechanical anisotropy of the lithospheric mantle, Earth Planet. Sci., Lett., 185, 199-210.

Vinnik, L. P., L. I. Makeyeva, A. Milev, and A. Y. Usenko (1992), Global patterns of azimuthal anisotropy and deformations in the continental mantle, Geophys. J. Int., 111, 433-447.

Wessel, P., and W. H. F. Smith (1991). Free software helps map and display data, Eos Trans. AGU, 72, 441, 445-446. 